\title{
Assessing the effect of arrival time of physician and cardiopulmonary resuscitation (CPR) team on the outcome of CPR
}

\author{
EBRAHIM EZZATI ${ }^{1}$, SAEED MOHAMMADI ${ }^{2}$, HASSANALI KARIMPOUR ${ }^{2}$, \\ JAVAD AMINI SAMAN ${ }^{2}$, AFSHIN GOODARZI ${ }^{3,4}$, AMIR JALALI $^{5}$, AFSHIN ALMASI ${ }^{6}$, \\ KAMRAN VAFAEI ${ }^{7}$, RASOOL KAWYANNEJAD $^{1, *}$
}

\begin{abstract}
${ }^{1}$ Department of Anesthesiology, School of Allied Medical Sciences, Kermanshah University of Medical Sciences, Kermanshah, Iran ${ }^{2}$ Department of Anesthesiology, School of Medicine, Kermanshah University of Medical Sciences, Kermanshah, Iran

${ }^{3}$ Department of Medical Emergency, School of Allied Medical Sciences, Kermanshah University of Medical Sciences, Kermanshah, Iran

${ }^{4}$ Department of Nursing, Hamadan University of Medical Sciences, Hamadan, Iran

${ }^{5}$ Department of Nursing, School of Nursing and Midwifery, Kermanshah University of Medical Sciences, Kermanshah, Iran

${ }^{6}$ Department of Biostatistics and Epidemiology, School of Health Public, Kermanshah University of Medical Sciences, Kermanshah, Iran

${ }^{7}$ Critical Care Nursing, Imam Reza Hospital, Kermanshah University of Medical Sciences, Kermanshah, Iran

*Corresponding author: Rasool Kawyannejad; Department of Anesthesiology, School of Allied Medical Sciences, Kermanshah University of Medical Sciences, Kermanshah 6719851351, Iran; Phone: +98 918969 9149; Fax: +98 833827 9697; E-mail: rasol_kavyan@yahoo.com
\end{abstract}

(Received: May 7, 2018; Revised manuscript received: May 19, 2018; Accepted: May 23, 2018)

\begin{abstract}
Introduction: Negligence of proper time and poor performance of resuscitation team can lead to more mortality and negative consequences of cardiac arrest, as well as less survival. This study was conducted with objective of determining the arrival time of physician and resuscitation team to survive the victims of cardiopulmonary arrest. Materials and methods: In this prospective and descriptive-analytic study, the resuscitation performance and the arrival time of resuscitation team in 143 inpatients who had been diagnosed with witnessed cardiopulmonary arrest were examined using a researcher-made checklist. Data analysis was performed using parametric and non-parametric statistical tests and SPSS. Results: Initial survival rate was 26.6\%. In general, the mean time of physician's presence after the code announcement in minutes and seconds was 02:31 $\pm 01: 22$. It was also 02:24 \pm 01:15 in successful cases and 02:34 01:25 in unsuccessful cases. Independent $t$-test did not show a significant difference between the physician's presence time and the rate of initial successful resuscitation $(p=0.504)$. The time of first shock after observing ventricular fibrillation/tachycardia (in minutes and seconds) was 01:30 $\pm 00: 47$. According to independent $t$-test, the aforementioned time was less than the mean time $(02: 31 \pm 01: 22)$ of physician's presence $(p<0.001)$. Conclusions: In this study, the initial survival rate in comparison to other regions in the country was almost more favorable and it was similar to global norms. In this study, the starting time of resuscitation was within the acceptable range. There was no relationship between the presence of physician and the initial survival rate of patients, as well as the use of defibrillator (by physician compared to other team members) and intubation with the initial survival rate. This could indicate the adequate performance of resuscitation team in the absence of physician on the condition of having sufficient knowledge and skill.
\end{abstract}

Keywords: cardiopulmonary resuscitation, medical staff, physician, survival rate, time

\section{Introduction}

Sudden cardiac arrest is one of the main causes of death [1]. Despite the development of therapeutic knowledge about resuscitation and its guidelines, cardiopulmonary arrest still has a high mortality rate [2]. Less than $20 \%$ of patients who receive in-hospital resuscitation survive and are discharged from the hospital [3]. With no regard to the main cause, cardiopulmonary arrest, even in successful cases, can cause a wide range of damages to vital organs, including the brain, and even can cause permanent disabilities [4]. Resuscitation team's lack of knowledge and skills, late detection of cardiac arrest and delay in resuscitation and chest compression, lack of effective

This is an open-access article distributed under the terms of the Creative Commons Attribution-NonCommercial 4.0 International License, which permits unrestricted use, distribution, and reproduction in any medium for non-commercial purposes, provided the original author and source are credited, a link to the CC License is provided, and changes - if any - are indicated. 
and prompt defibrillation, and lack of attention to postresuscitation care are among the most important factors in the failure of resuscitation and reduction of survival rates [4-10].

In other words, overlooking the time factor as a vital factor and poor performance of the cardiopulmonary resuscitation (CPR) team can lead to an increase in mortality, as well as to an increase in the adverse effects of cardiac arrest.

The resuscitation team consists of physicians and clinical staff who are qualified in providing airway and establishing venous access, cardiac chest compression, drug delivery, and the use of defibrillation [11]. Various studies show that the timely and effective presence of the rescuers, including the resuscitation physician as a leader, is essential in increasing the survival rate of the patients and the success of resuscitation $[6-8,11,12]$.

In spite of the emphasis in the clinical guidelines on the early detection of cardiac arrest and immediate intervention by the CPR team $[1,13,14]$, unfortunately, there have been very few studies conducted on the arrival time of physician and resuscitation team and its association with the outcome of resuscitation. Therefore, this study was conducted with the objective of evaluating the arrival time of physician and resuscitation team at Imam Reza Hospital of Kermanshah in Iran during 2018. In addition, regarding the secondary objectives, the initial survival rate and its effective factors were also examined.

\section{Materials and Methods}

This research was a single centered prospective, observational, and descriptive-analytical study. This study was conducted by financial and spiritual support of Kermanshah University of Medical Sciences, Kermanshah, Iran (project no. 95648). Ethics approval was obtained from Ethics Committee Board of this university. (IR.KUMS. REC.1395.711). This committee waived the necessity of written informed consent. It was conducted at Imam Reza Hospital of Kermanshah, as the largest educational hospital in west of Iran, for a period of 9 months from April 2017 to December 2017 through the census method. In this study, the resuscitation procedure was assessed using a researcher-made checklist in 195 patients who had witnessed cardiopulmonary arrest in general wards and received cardiac chest compression or defibrillation. The checklist contained information such as age, gender, cause of hospitalization, work shift, time and place of cardiac arrest, the cause of cardiac arrest, initial cardiac rhythm, arrival time of resuscitation team, time of the first shock, performance time of tracheal intubation, and duration of resuscitation efforts. The final outcome of the resuscitation was recorded as unsuccessful resuscitation, patient death, and initial successful resuscitation/survival, namely, return of spontaneous circulation (ROSC) for at least $30 \mathrm{~min}$. Time-related data were recorded by the head nurse or supervisor during the cardiopulmonary arrest. After matching the reported data with the patient's history, the resuscitation form, and the supervisor's report, the data were recorded in the checklist. Inclusion criteria were as follows: non-traumatic cardiopulmonary arrest, absence of tracheal tube in the patient, lack of do-not-resuscitate order from the responsible physician and exclusion criteria, lack of resuscitation code announcement, nonintubated patients, ROSC after resuscitation initiation, history of severe pulmonary disease, and cardiac arrest due to hypothermia. In addition, patients with incomplete data about their resuscitation were excluded from the survey. Finally, data from 143 subjects were analyzed using a checklist and the rest were excluded from the study due to lack of the inclusion criteria. Parametric and non-parametric statistical methods and SPSS software (version 22) were used to analyze the data.

\section{Results}

Out of the 143 resuscitation cases, 39 cases $(26.6 \%)$ resulted in the patient's initial survival and ROSC of greater than or equal to $30 \mathrm{~min}$ and 104 cases $(73.4 \%)$ were unsuccessful.

About $57.3 \%$ of participants ( 82 cases) were male and their mean age was $65.63 \pm 15.09$ years with a range of 39-90 years old. The relationship between initial survival and gender of resuscitated cases was not significant $(p=0.643$; Table I). But the independent $t$-test demonstrated a significant relationship between the age of samples and initial survival of patients $(p<0.001)$, in a way that the mean age of patients with successful initial resuscitation was $55.97 \pm 10.40$ years and it was $66.17 \pm 14.79$ years in unsuccessful cases.

In this study, the most commonly occurring places of cardiopulmonary arrest were respectively in internal ward $(40.6 \%)$, neurology ward $(22.4 \%)$, infectious ward $(16.8 \%)$, surgery ward $(10.5 \%)$, and oncology ward $(9.8 \%)$. According to the $\chi^{2}$ test, there was no relationship between the place of occurrence and the initial success rate of resuscitation $(p=0.552$; Table $I)$.

The incidence rate of CPR cases were $28.7 \%$, $26.6 \%$, and $44.8 \%$ in the morning, evening, and night shifts, respectively, while the highest initial success rate of resuscitation was seen during the morning shift $(39 \%)$ and the lowest was seen during the night shift $(17.2 \%)$. The $\chi^{2}$ test showed a significant relationship between the work shift and initial success rate $(p=0.039$, Table I).

In $35 \%$ of cases, cardiac causes (i.e., cardiovascular diseases and problems, such as myocardial infarction, cardiac 
Table I Frequency distribution and percentage of some factors associated with successful initial CPR

\begin{tabular}{|c|c|c|c|c|}
\hline Variable & CPR outcome & $\begin{array}{c}\text { No. of } \\
\text { unsuccessful CPR }\end{array}$ & $\begin{array}{c}\text { No. of initial } \\
\text { successful CPR }\end{array}$ & Statistical test \\
\hline Gender & $\begin{array}{l}\text { Female } \\
\text { Male }\end{array}$ & $\begin{array}{l}46(75.4 \%) \\
59(72 \%)\end{array}$ & $\begin{array}{l}15(24.6 \%) \\
23(28 \%)\end{array}$ & Pearson $\chi^{2}, p=0.643$ \\
\hline Place of cardiac arrest & $\begin{array}{l}\text { Infectious ward } \\
\text { Surgery ward } \\
\text { Internal ward } \\
\text { Neurology ward } \\
\text { Oncology ward }\end{array}$ & $\begin{array}{l}15(62.5 \%) \\
10(66.7 \%) \\
44(75.9 \%) \\
23(71.9 \%) \\
12(85.7 \%)\end{array}$ & $\begin{array}{r}9(37.5 \%) \\
5(33.3 \%) \\
14(24.1 \%) \\
9(28.1 \%) \\
2(14.3 \%)\end{array}$ & Pearson $\chi^{2}, p=0.552$ \\
\hline Cause of cardiac arrest & $\begin{array}{l}\text { Cardiac causes } \\
\text { CVA } \\
\text { Internal causes } \\
\text { Respiratory causes } \\
\text { Renal causes } \\
\text { Infectious causes } \\
\text { Cancer }\end{array}$ & $\begin{array}{l}29(58 \%) \\
18(69.2 \%) \\
14(82.4 \%) \\
12(75 \%) \\
11(91.7 \%) \\
10(83.3 \%) \\
10(100 \%)\end{array}$ & $\begin{aligned} 21 & (42 \%) \\
8 & (30.8 \%) \\
3 & (17.6 \%) \\
4 & (25 \%) \\
1 & (8.3 \%) \\
2 & (16.7 \%) \\
0 & (0 \%)\end{aligned}$ & Pearson $\chi^{2}, p=0.042$ \\
\hline Work shift & $\begin{array}{l}\text { Morning } \\
\text { Evening } \\
\text { Night }\end{array}$ & $\begin{array}{l}25(61 \%) \\
26(68.4 \%) \\
53(82.8 \%)\end{array}$ & $\begin{array}{l}16(39 \%) \\
12(31.6 \%) \\
11(17.2 \%)\end{array}$ & Pearson $\chi^{2}, p>0.001$ \\
\hline Duration of resuscitation efforts & $\begin{array}{l}\text { Less than } 30 \mathrm{~min} \\
\text { More than } 30 \mathrm{~min}\end{array}$ & $\begin{array}{l}32(53.3 \%) \\
72(86.7 \%)\end{array}$ & $\begin{array}{l}28(7.46 \%) \\
11(13.31 \%)\end{array}$ & Pearson $\chi^{2}, p>0.001$ \\
\hline First rhythm & $\begin{array}{l}\mathrm{VF} / \mathrm{VT} \\
\text { Asystole } \\
\text { Bradycardia }\end{array}$ & $\begin{array}{l}12(27.9 \%) \\
63(92.6 \%) \\
21(91.3 \%)\end{array}$ & $\begin{array}{c}31(72.1 \%) \\
5(92.6 \%) \\
2(8.7 \%)\end{array}$ & Pearson $\chi^{2}, p>0.001$ \\
\hline Time of tracheal intubation & $\begin{array}{l}\text { PEA } \\
<1 \mathrm{~min} \\
1-5 \mathrm{~min}\end{array}$ & $\begin{array}{r}8(88.9 \%) \\
34(75.6 \%) \\
70(71.4 \%)\end{array}$ & $\begin{array}{r}1(11.1 \%) \\
11(24.4 \%) \\
28(28.6 \%)\end{array}$ & Fisher's exact test, $p=0.689$ \\
\hline Medical degrees & $\begin{array}{l}\text { GP } \\
\text { Associate specialist }\end{array}$ & $\begin{array}{l}24(80 \%) \\
80(70.8 \%)\end{array}$ & $\begin{array}{c}6(20 \%) \\
33(29.2 \%)\end{array}$ & Fisher's exact test, $p=0.303$ \\
\hline Work experience & $\begin{array}{l}<5 \text { years } \\
1-5 \text { years } \\
>5 \text { years }\end{array}$ & $\begin{array}{l}21(63.6 \%) \\
40(71.4 \%) \\
43(79.6 \%)\end{array}$ & $\begin{array}{l}12(4.36 \%) \\
16(28.6 \%) \\
11(20.4 \%)\end{array}$ & Pearson $\chi^{2}, p=0.257$ \\
\hline
\end{tabular}

CPR: cardiopulmonary resuscitation; CVA: cerebrovascular accidents; VF/VT: ventricular fibrillation/tachycardia; tachycardia; PEA: pulseless electrical activity; GP: general physician

tamponade, coronary artery disease, etc.) were the cause of cardiopulmonary arrest. Other causes of cardiopulmonary arrest were cerebrovascular accidents, internal causes (such as coagulopathies and metabolic diseases), respiratory cause, renal cause, infectious cause, and cancer with $18.2 \%$, $11.9 \%, 11.2 \%, 8.4 \%, 8.4 \%$, and $7 \%$, respectively. $\chi^{2}$ test showed a significant relationship between cardiopulmonary arrest risk factors, especially cardiac causes, and initial success rate of resuscitation $(p=0.042$; Table $I)$.

At the time of cardiopulmonary arrest, the first rhythm observed on the electrocardiogram in $47.6 \%$ of cases was asystole, in $30.1 \%$ of cases was ventricular fibrillation/ tachycardia (VF/VT), in 16.1\% of cases was bradycardia, and in $6.3 \%$ of cases was without pulse. Among the mentioned rhythms, the highest survival rate was for $\mathrm{VF} / \mathrm{VT}$ shockable rhythms, and $72.1 \%$ of initial successful resuscitations had these kinds of rhythms. $\chi^{2}$ test suggested a significant relationship between the type of cardiac rhythm, mainly VF/VT shockable rhythms, and the initial success rate $(p<0.001$; Table $I)$.

Considering the witnessed cardiopulmonary arrests, in all cases, the time of resuscitation initiation by the nursing team was less than 1 min.

In general, the mean time of physician's presence after the code announcement was 02:31 $\pm 01: 22$. It was 02:24 01:15 in successful cases and 02:34 \pm 01:25 in unsuccessful cases. Independent $t$-test did not show any significant difference between the physician's presence time and the initial success rate $(p=0.504)$.

In this study, mean time of the first shock after appearance of VF/VT was 01:30 \pm 00:47; and independent $t$-test demonstrated that the aforementioned time was significantly less than the mean time of physician's presence $(02: 31 \pm 01: 22 ; p<0.001)$. 
Ezzati et al.

Table II Effective indicators in initial survival rate of CPR based on multivariate logistic regression model

\begin{tabular}{|c|c|c|c|c|}
\hline \multirow[b]{2}{*}{ Indicators } & \multirow[b]{2}{*}{$\mathrm{OR}$} & \multirow[b]{2}{*}{$p$ value } & \multicolumn{2}{|c|}{$95 \% \mathrm{CI}$ for $\mathrm{EXP}(\mathrm{B})$} \\
\hline & & & Upper & Lower \\
\hline Age (years) & 1.03 & 0.21 & 1.08 & 0.98 \\
\hline Gender (male/female) & 0.96 & 0.94 & 3.14 & 0.29 \\
\hline Duration of CPR $(<30 \mathrm{~min} />30 \mathrm{~min})$ & 0.21 & 0.01 & 0.73 & 0.06 \\
\hline \multicolumn{5}{|l|}{ Dysrhythmia (PEA) } \\
\hline $\mathrm{VF} / \mathrm{VT}$ & 0.06 & 0.02 & 0.74 & 0.005 \\
\hline Asystole & 2.13 & 0.56 & 27.54 & 0.15 \\
\hline Bradycardia & 1.86 & 0.66 & 30.2 & 0.15 \\
\hline \multicolumn{5}{|l|}{ Diagnosis (infectious diseases) } \\
\hline Cardiovascular disease & 0.72 & 0.77 & 6.64 & 0.07 \\
\hline CVA & 0.97 & 0.98 & 10.57 & 0.09 \\
\hline Respiratory problems & 0.92 & 0.95 & 13.28 & 0.06 \\
\hline Internal disease, renal disease, and cancer & 3.69 & 0.29 & 42.98 & 0.31 \\
\hline \multicolumn{5}{|l|}{ Shift (night) } \\
\hline Shift (morning) & 0.29 & 0.05 & 1.21 & 0.07 \\
\hline Shift (evening) & 0.21 & 0.04 & 0.94 & 0.05 \\
\hline
\end{tabular}

The adjusted odds ratio (OR) are age, gender, duration of CPR, dysrhythmia, diagnosis, and shift. CI: confidence interval; CPR: cardiopulmonary resuscitation; CVA: cerebrovascular accidents; VF/VT: ventricular fibrillation/tachycardia; PEA: pulseless electrical activity

In $31.5 \%$ of cases, the performance time of tracheal intubation by personnel was less than $1 \mathrm{~min}$ and in the remaining $68.5 \%$ of cases, it was $1-5 \mathrm{~min}$. Fisher's exact test did not show a significant relationship between the performance time of tracheal intubation and the initial success rate of resuscitation $(p=0.689$; Table $I)$.

The duration of resuscitation efforts in $58.7 \%$ of the cases was more than $30 \mathrm{~min}$ and in the remaining $41.3 \%$ of cases, it was less than $30 \mathrm{~min}$. $\chi^{2}$ test found a significant relationship between $\mathrm{CPR}$ duration of more than $30 \mathrm{~min}$ and less than $30 \mathrm{~min}$ and the initial success rate $(p<0.001 ;$ Table I). The success rate was lower in those who had CPR duration of more than $30 \mathrm{~min}$ and in $86.7 \%$ of patients who had CPR duration of more than $30 \mathrm{~min}$, the resuscitation was unsuccessful.

About $79 \%$ of the physicians who were the leader of CPR team were associate specialists and $20.3 \%$ were general practitioners. About $37.8 \%$ of the physicians had clinical work experience of more than 10 years, $39.2 \%$ had 5-10 years of clinical work experience, and $23.1 \%$ had less than 5 years of such experience. Fisher's exact test and $\chi^{2}$ test did not show a significant relationship between the medical degrees, years of work experience, and initial success rate $(p>0.05$; Table $I)$.

After considering the confounding variables, the logistic regression test showed that cardiac rhythms of VF/ VT [odds ratio $(\mathrm{OR})=0.06, p=0.02]$, duration of resuscitation efforts $(\mathrm{OR}=0.21, p=0.01)$, morning shift $(\mathrm{OR}=0.29, p=0.05)$, and evening shift $(\mathrm{OR}=0.21$, $p=0.04)$ had significant relationship with initial outcome of CPR (Table II).

\section{Discussion}

In this study, $26.6 \%$ of the resuscitation efforts resulted in the initial survival rate of the patient and ROSC of greater than or equal to $30 \mathrm{~min}$. In the study of Shao et al. [2] in China, the initial survival rate and ROSC were $35.5 \%$ due to the lower mean age of the samples and selecting them from the emergency ward (ER) and intensive care unit (ICU) that were not addressed in our study. Initial survival rate of CPR in the study of Nolan et al. [15] in England was reported to be $45 \%$, which was justifiable due to the different definition of this study - ROSC of greater than or equal to $20 \mathrm{~min}$ - and the different study population. The study of Mohammadnejad et al. [16] in Iran also reported the initial survival rate of $28.4 \%$. Considering the fact that the rate of successful CPR in Iran is about $15.3 \%-32 \%$ [17], we can say that the initial survival rate in this study, comparing to other parts of the country, is favorable and is close to the global norms.

Although in some studies, such as Shao et al.'s [2] and Movahedi et al.'s [18], the females had a direct and positive relationship with initial successful rate of CPR and women were more likely to survive than men, in this study just like the study of Miranzadeh et al. [8], there was no significant relationship between the gender and CPR 
outcome. The existence or non-existence of a relationship between successful initial survival rate and gender in different studies can be attributed to the sample size and different numbers of each gender in these studies. Male gender is considered as a risk factor for heart disease, and low rate of survival following the CPR in this group is not unexpected [18]. Unlike this study, this study did not show a relationship between age and CPR outcome [8].

In this study, there was a significant relationship between the age of the subjects and the initial survival rate, and like the studies of Shao et al. [2] and Nolan et al. [15], the likelihood of successful CPR was lower at older ages $(p<0.001)$. In addition, the mean age in successful initial CPR cases was $55.97 \pm 10.40$ years and it was $66.17 \pm 14.79$ years in unsuccessful cases. In the study of Shao et al. [2], the age below 60 years was effective in the rate of survival and successful CPR. In the study of Mohammadnejad et al. [16], none of the patients over 60 years were discharged from the hospital after the CPR.

In this study, unlike Shao et al. [2] and Nolan et al. [15], the time of attending physician and the inclusion criteria in intensive care, emergency, and operating rooms wards have not examined. In addition, this study declared that there was no relationship between the place of arrest occurrence and the initial success rate of CPR, which was consistent with the study of Alizadeh et al. [9].

Furthermore, the highest initial survival rate was significantly seen in the morning shift and the lowest was seen at night. Many other studies also showed higher rate of successful CPR in the morning shift than in the night shift $[6,8,15,16]$. The low survival rate of patients following in-hospital cardiac arrest at night can be due to less readiness and low number of staff, as well as slower reaction of CPR team at night shifts $[8,16]$.

In $35 \%$ of cases, cardiovascular disease was the main cause of cardiopulmonary arrest. In the study of Shao et al. [2], in $47.6 \%$ of in-hospital CPR cases, heart disease was the main cause of cardiopulmonary arrest. In the samples from the Bergum et al.'s [19] study, 60\% and $20 \%$ of cases of cardiac arrest were related to cardiac and hypoxia causes; moreover, initial survival rate for cardiac causes was $30 \%$, which was $12 \%$ lower than this study. In this study, the lowest success rate was related to infectious diseases and cancer, suggesting that the patients with underlying advanced disease such as cancer had less chance of successful resuscitation; likewise in the study of Mohammadnejad et al., none of the cancer patients had resuscitation. On the other hand, in the study of Movahedi et al. [18], there was a significant relationship between diabetes and 24-h survival rate, in a way that the rate of unsuccessful resuscitation was higher in diabetic patients. Alizadeh et al. [9] also suggested that the highest frequency was related to cardiovascular disease and similar to this study, there was a statistically significant relationship between the initial cause of cardiac arrest and CPR results.
In this study, at the time of cardiopulmonary arrest, the most observed rhythms were asystole $(47.6 \%)$ and $\mathrm{VF} / \mathrm{VT}(30.1 \%)$. In addition, the greatest chance of successful initial resuscitation was in VF/VT rhythms. In the study of Bergum et al. [19], in $28 \%$ of the cases, the first observed rhythms were VF/VT shockable rhythms, which were close to the frequency rate in this stud. In the studies of Shao et al. in China and Nolan et al. in Britain, the most reported arrhythmia was asystole. In these two studies, about $16 \%$ of patients had initial VF/VT cardiac rhythm, which could be due to the inclusion of ER and ICU wards patients, the lower age range of the subjects, and the differences in the inclusion criteria; moreover, in these two studies, similar to our study, the survival rate and the initial resuscitation rate were higher in the presence of shockable rhythms [2, 15].

Furthermore, in this study, the initial resuscitation was successful in $72.1 \%$ of patients who were resuscitated with clinical signs of VF/VT. Likewise, in the study of Bergum et al. [19], 53\% of these cases resulted in successful resuscitation and discharge from the hospital, indicating a good prognosis for these rhythms in CPR. The study of Hirlekar et al. [6] in this regard is consistent with this study. It was also seen that in the study of Mohammadnejad et al. [16], the survival and discharge rates of patients with shockable rhythms were significantly higher than for the patients with non-shockable rhythms, and there was a significant relationship between the type of initial cardiac rhythm, being a shockable rhythm, and the final outcome of CPR. In addition, there was clear evidence of higher survival rate due to rapid use of defibrillator, after cardiac arrest [17]. It can be said that for every 1-min delay in defibrillation, the survival rate of patients reduces by $7 \%-10 \%$, and the time between VF and shock must be less than $3 \mathrm{~min}[8,16,17]$. This can be due to the susceptibility of these rhythms to the shock and back into normal rhythm, in the time of promptly performed shock [16].

The CPR duration in $58.7 \%$ of the subjects was more than $30 \mathrm{~min}$ and in $41.3 \%$ of the subjects, it was less than $30 \mathrm{~min} . \chi^{2}$ test demonstrated a significant relationship between CPR duration of greater than or less than $30 \mathrm{~min}$ and initial survival rate $(p<0.001$; Table I); and the likelihood of success was less in those with CPR duration of more than $30 \mathrm{~min}$, as in $86.7 \%$ of these cases, the resuscitation was unsuccessful. The mean duration of CPR in the study of Borimnejad et al. [20] was 25:48 \pm 11:06 in minutes and seconds. In the study of Miranzadeh et al. [8], the main predictive factors of survival were the arrival time of resuscitation team and the short duration of CPR. In their study, the mean duration of CPR was 35:11 $11: 42$. In the study of Mohammadnejad et al. [16], the most important indicators in discharging patients from hospital consisted of heart rhythm, arrival time of resuscitation team, and CPR 
duration. Similar results were seen in the study of Alizadeh et al. [9].

Nurses are the first members of CPR team who encounter the patients who need CPR in the early stages, and they usually begin to perform CPR before the arrival of physicians; thus, they play a vital role in the patient's life [21]. In this study, the starting time of CPR was less than 1 min by the nursing team. The study of Bergum et al. [19] in a Norwegian hospital was similar to this study with the mean time of $1 \mathrm{~min}$ in CPR initiation. However, in the study of Shao et al. [2], just in $53.5 \%$ of the subjects the CPR was performed in less than or equal to $1 \mathrm{~min}$, which could be due to overcrowded wards and inclusion of non-specialized hospitals. Moreover, considering the inclusion of ER and ICU in the study of Miranzadeh et al. [8] in Kashan, the starting time of CPR was $2: 29 \pm 2: 40 \mathrm{~min}$, which was significantly more than the time spent in this study. The study of Herlitz et al. [22] suggested a two-time greater survival rate of CPR when the initiation of CPR was less than $1 \mathrm{~min}$, comparing with the cases that started CPR in more than $1 \mathrm{~min}$. Borimnejad et al. [20] also showed that for $79.3 \%$ of the cases, the CPR team arrived in $0-2 \mathrm{~min}$; it indicated that this study had a relatively more favorable status than their study.

The performance time of tracheal intubation by personnel was between 1 and $5 \mathrm{~min}$ in $68.5 \%$ of the cases, and there was not any difference between the performance time of tracheal intubation and initial success rate of resuscitation. In the study of Miranzadeh et al. [8], in more than $90 \%$ of cases, tracheal intubation was performed in less than $5 \mathrm{~min}$, and similar to our study, there was no difference between the duration of intubation and the outcome of CPR, which could mention the successful performance with non-invasive equipment, such as ambu bag and mask.

Overall, the mean time of physician's arrival after the code announcement in minutes and seconds was $02: 31 \pm 01: 22$, and there was no difference between the physician's arrival time and the initial success rate of resuscitation $(p=0.504)$. This finding did not support the study of McNeill and Bryden [23] in which the responses to life-threatening conditions, such as cardiopulmonary arrest, necessarily improved in the presence of a physician with vital care skills.

In this study, the duration of first shock after seeing $\mathrm{VF} / \mathrm{VT}$ was $01: 30 \pm 47: 00$, which was less than the mean time of physician's arrival $(02: 31 \pm 01: 22 ; p<0.001)$. Mean time of the first heart shock in the study of Mohammadnejad et al. [16] was 3:69 $\pm 01: 89$, which was much more than that of this study. Time of the first shock in our study was less than that of Hirlekar et al. [6], as in $20 \%$ of patients aged $70-89$ years, there were more than 3-min delay in ventricular defibrillation.

In the hospital we reviewed, the nursing staff had to pass mandatory annual retraining courses of theoretical and practical training for CPR and the use of defibrillators based on American Heart Association's CPR guidelines, which could play a key role in the successful resuscitation of cardiopulmonary arrest victims. Holding regular and systematic retraining programs on CPR is an overarching factor in the success of CPR and increasing of survival rate [12]. While Shao's study in China stated that a large number of staff in general or outpatient wards needed retraining courses of CPR [2].

Logistic regression analysis showed that VF/VT rhythms $(\mathrm{OR}=0.06, p=0.02), \mathrm{CPR}$ duration $(\mathrm{OR}=$ $0.21, p=0.01)$, morning shifts $(\mathrm{OR}=0.29, p=0.05)$, and evening shifts $(\mathrm{OR}=0.21, p=0.04)$ had a significant relationship with initial outcome of CPR.

In this study, multiple logistic regression showed that the most important indicators for initial successful CPR included age, VF/VT rhythms, CPR duration of less than $30 \mathrm{~min}$, and morning shift and evening shift in comparison to night shift.

In the study of Miranzadeh et al. [8], less CPR duration and quick arrival of CPR team were recognized as the main predictive factors of survival. Furthermore, logistic regression in the study of Movahedi et al. [18] showed that the duration of hospitalization and CPR had significant statistical effects on the survival of cardiopulmonary arrest victims; in patients with longer duration of hospitalization before CPR or with longer CPR duration, the likelihood of 24-h survival was less. The results of Alizadeh et al.'s [9] study also showed that more likelihood of success was seen in the patients of younger age, the shorter CPR duration, and CPR due to non-cardiac causes. In the study of Mohammadnejad et al. [16], the most important predictive factors of survival were comprised of morning shift, shorter CPR duration, and VF/VT rhythms, which were consistent with our findings; and the study emphasized the significance of these three variables in predicting the survival of resuscitated patients.

In this study, the time of resuscitation, the arrival of physicians and staff, and the time of first shock and intubation were examined, but the time of first injection of drugs, the first chest compression, and their relationship to initial survival rate were not studied, so they were considered as limitations of our study. The presence of a cardiologist or cardiology resident in the resuscitation team could help the accurate diagnosis of initial cardiac rhythm. Given the fact that possible causes of cardiopulmonary arrest were just recorded based on the physician's diagnosis and report, these data were considered with caution. In addition, larger sample size could help the generalization of outcomes. Besides, conducting further studies on this issue and in other hospitals, including educational and non-educational hospitals, is recommended.

\section{Conclusions}

The results of this study confirm that successful CPR is dependent on accurate, effective and timely commitment, 
and performance of all members of CPR team and not just on the physician as a leader of team. For the success of performance and increasing the survival rate, other studies have also emphasized the discipline and solidarity of all members of CPR team and not just the CPR team's physician $[7,20,24]$. In this study, time of CPR initiation was within the acceptable range. Besides, there was no relationship between the arrival time of physician and the survival rate, and also between the use of defibrillator and intubation and the initial survival rate; these could indicate the proper performance of CPR team in the absence of physician, assuming to have sufficient knowledge and skills.

$$
\text { ** * }
$$

Funding sources: All credits of this project (project number: 95648) were funded by Research and Technology Deputy of Kermanshah University of Medical Sciences in Iran.

Authors' contribution: SM, HK, JAS, AG, and AJ collected the data of the manuscript. AA contributed in data analysis. EE and RK wrote the manuscript, designed the study, supervised the group, and revised the manuscript prior to submission.

Conflict of interest: The authors declare no conflict of interest in relation to the work.

Acknowledgements: The authors would like to show their gratitude to the director and the manager of Imam Reza Hospital, the nursing director, and all the staff of investigated wards who provided facilities that greatly assisted the research. This study was conducted by financial sponsoring and continuous support of Kermanshah University of Medical Sciences (project no. 95648).

\section{References}

1. Kleinman ME, Brennan EE, Goldberger ZD, Swor RA, Terry M, Bobrow BJ, Gazmuri RJ, Travers AH, Rea T: Part 5: Adult basic life support and cardiopulmonary resuscitation quality. 2015 American heart association guidelines update for cardiopulmonary resuscitation and emergency cardiovascular care. Circulation 132, S414-S435 (2015)

2. Shao F, Li CS, Liang LR, Qin J, Ding N, Fu Y, Yang K, Zhang GQ, Zhao L, Zhao B, Zhu ZZ, Yang LP, Yu DM, Song ZJ, Yang QL: Incidence and outcome of adult in-hospital cardiac arrest in Beijing, China. Resuscitation 102, 51-56 (2016)

3. Fendler TJ, Spertus JA, Kennedy KF, Chan PS: Association between hospital rates of early do-not-resuscitate orders and favorable neurological survival among survivors of inhospital cardiac arrest. Am Heart J 193, 108-116 (2017)

4. Callaway CW, Donnino MW, Fink EL, Geocadin RG, Golan E, Kern KB, Leary M, Meurer WJ, Peberdy MA, Thompson TM, Zimmerman JL: Part 8: Post-cardiac arrest care. 2015 American heart association guidelines update for cardiopulmonary resuscitation and emergency cardiovascular care. Circulation 132, S465-S482 (2015)

5. Sodhi K, Singla MK, Shrivastava A: Impact of advanced cardiac life support training program on the outcome of cardiopulmonary resuscitation in a tertiary care hospital. Indian J Crit Care Med $15,209-212(2011)$
6. Hirlekar G, Karlsson T, Aune S, Ravn-Fischer A, Albertsson P, Herlitz J, Libungan B: Survival and neurological outcome in the elderly after in-hospital cardiac arrest. Resuscitation 118, 101-106 (2017)

7. Henderson SO, Ballesteros D: Evaluation of a hospital-wide resuscitation team: Does it increase survival for in-hospital cardiopulmonary arrest? Resuscitation 48, 111-116 (2001)

8. Miranzadeh S, Adib-Hajbaghery M, Hosseinpour N: A prospective study of survival after in-hospital cardiopulmonary resuscitation and its related factors. Trauma Mon 21, e31796 (2016)

9. Alizadeh M, Mousavi Movahed M, Sadredini S, Mostafavi A, Fathi $\mathrm{M}$ : The evaluation of the resuscitation results and its associated factors. Tehran Univ Med J 74, 640-644 (2016)

10. Montazar SH, Amooei M, Sheyoei M, Bahari M: Results of CPR and contributing factor in Emergency Department of Sari Imam Khomeini Hospital, 2011-2013. J Mazandaran Univ Med Sci 24, 53-58 (2014)

11. Chamberlain B, Donley K, Maddison J: Patient outcomes using a rapid response team. Clin Nurse Spec 23, 11-12 (2009)

12. Kavosi A, Parvinian Nasab AM, Hessam M, Shariati A, Jouybari L, Sanagu A: Barriers to the success of cardiopulmonary resuscitation teams from the perspective of nurses. Jorjani Biomed J 1, 16-22 (2014)

13. Valinejadi A, Sadoughi F, Salehi M: Diabetes knowledge translation status in developing countries: A mixed method study among diabetes researchers in case of Iran. Int J Prev Med 7, 33 (2016)

14. Hassanzad M, Orooji A, Valinejadi A, Velayati A: A fuzzy rulebased expert system for diagnosing cystic fibrosis. Electron Phys 9, 5974-5984 (2017)

15. Nolan JP, Soar J, Smith GB, Gwinnutt C, Parrott F, Power S, Harrison DA, Nixon E, Rowan K, National Cardiac Arrest Audit: Incidence and outcome of in-hospital cardiac arrest in the United Kingdom National Cardiac Arrest Audit. Resuscitation 85, 987-992 (2014)

16. Mohammadnejad E, Vanaki Z, Ahmadi F, Salari A: Survival rate and outcomes of cardiopulmonary resuscitation. J Crit Care Nurs 3, e7118 (2010)

17. Abdi A, Aliyari S, Pishgooie A, SeyyedMazhari M, Nazari S: New aspects in basic cardiopulmonary resuscitation according to the 2015 guideline. Mil Caring Sci 3, 56-67 (2016)

18. Movahedi A, Kavosi A, Behnam Vashani H, Mohammadi G, Mehrad Majd H, Malekzadeh J: 24 hour survival rate and its determinants in patients with successful cardiopulmonary resuscitation in Ghaem Hospital of Mashhad. J Neyshabur Univ Med Sci $3,56-63$ (2016)

19. Bergum D, Nordseth T, Mjølstad OC, Skogvoll E, Haugen BO: Causes of in-hospital cardiac arrest - Incidences and rate of recognition. Resuscitation 87, 63-68 (2015)

20. Borimnejad L, Rasouli M, Nikbakht Nasrabadi AR, Mohammadi H, Kheirati L: Effect of trained cardiopolmonary resuscitation team on the outcomes of cardiopolmonary resuscitation. J Babol Univ Med Sci 10, 55-61 (2008)

21. Zahedmehr A, Daram Z, Totonchi M: The effect of education by video self-assessment on nurses' knowledge and performance in cardiopulmonary resuscitation. Cardiovas Nurs J 4, 32-39 (2016)

22. Herlitz J, Bång $A$, Aune $S$, Ekström L, Lundström G, Holmberg S: Characteristics and outcome among patients suffering in-hospital cardiac arrest in monitored and non-monitored areas. Resuscitation 48, 125-135 (2001)

23. McNeill G, Bryden D: Do either early warning systems or emergency response teams improve hospital patient survival? A systematic review. Resuscitation 84, 1652-1667 (2013)

24. Moretti MA, Cesar LA, Nusbacher A, Kern KB, Timerman S, Ramires JA: Advanced cardiac life support training improves long-term survival from in-hospital cardiac arrest. Resuscitation $72,458-465$ (2007) 